\title{
Nanostructured $\mathrm{LiMPO}_{4}(\mathrm{M}=\mathrm{Fe}, \mathrm{Mn}, \mathrm{Co}, \mathrm{Ni})$ - carbon composites as cathode materials for Li-ion battery
}

\author{
L. Dimesso ${ }^{1, a}$, C. Spanheimer ${ }^{1}$, T.T.D. Nguyen ${ }^{1}$ R. Hausbrand ${ }^{1}$ and W. Jaegermann ${ }^{1,2}$ \\ ${ }^{1}$ Technische Universitaet Darmstadt, Materials Science Department, Petersenstrasse 23, D-64287 \\ Darmstadt, Germany \\ ${ }^{2}$ Center of Smart Interfaces, Darmstadt University of Technology, Petersenstrasse 32, D-64287, \\ Darmstadt, Germany
}

\begin{abstract}
Nanostructured materials are considered to be strong candidates for fundamental advances in efficient storage and/or conversion. In nanostructured materials transport kinetics and surface processes play determining roles. This work describes recent developments in the synthesis and characterization of composites which consist of lithium metal phosphates $\left(\mathrm{LiMPO}_{4}, \mathrm{M}=\mathrm{Fe}, \mathrm{Mn}, \mathrm{Co}, \mathrm{Ni}\right)$ coated on nanostructured carbon supports (unordered nanofibers, foams). The composites have been prepared by coating the carbon structures in aqueous (or polyols) solutions containing lithium, metal ions and phosphates. After drying out, the composites have been thermally treated at different temperatures (between $600-780^{\circ} \mathrm{C}$ ) for $5-12$ hours under nitrogen. The formation of the olivine structured phase was confirmed by the X-ray diffraction analysis on powders prepared under very similar conditions. The surface investigation revealed the formation of an homogeneous coating of the olivine phase on the carbon structures. The electrochemical performance on the composites showed a dramatic improvement of the discharge specific capacity (measured at a discharge rate of $\mathrm{C} / 25$ and room temperature) compared to the prepared powders. The delivered values were $105 \mathrm{mAhg}^{-1}$ for $\mathrm{M}=\mathrm{Fe}, 100 \mathrm{mAhg}^{-1}$ for $\mathrm{M}=\mathrm{Co}, 70 \mathrm{mAhg}^{-1}$ for $\mathrm{M}=\mathrm{Mn}$ and $30 \mathrm{mAhg}^{-1}$ for $\mathrm{M}=\mathrm{Ni}$ respectively.
\end{abstract}

\section{Introduction}

Due to the increase in demand for oil, associated price increases, and enviromental issues, significant progress has been made in the development of renewable energy technologies such as solar cells, fuel cells and biofuels. One of the main challenges in using renewable energies is the need of an efficient, cheap and reliable storage device. The lithium-ion battery is a representative system for such electrochemical energy storage and conversion. In the last years, there has been intensive research activity into new electrode materials for the next generation of rechargeable lithium-ion batteries (LIBs), particularly for use in hybrid electric vehicles [1]. Olivine-structured orthophosphates $\mathrm{LiMPO}_{4}(\mathrm{M}=\mathrm{Fe}, \mathrm{Mn}, \mathrm{Co}$ and $\mathrm{Ni}$ ) have been proposed as viable alternatives to the conventional cathode material. The olivine phosphates have high energy storage capacity combined

\footnotetext{
a e-mail : ldimesso@surface.tu-darmstadt.de
} 
with electrochemical and thermal stability, and high voltages versus $\mathrm{Li}^{+} / \mathrm{Li}$ couple [2]. Further, olivine-structured materials are resistant to overcharge, thermal degradation, and inherently safer than oxides that may release oxygen at inopportune times. However, the covalent bonding of $\mathrm{PO}_{4}{ }^{3-}$ reduces the ionic conductivities of the materials which lead to additional treatments with conductive aids such as carbon coating or metal doping to improve the electrochemical properties.

A new approach to enhance the effects of the carbon content has been reported recently by our group [3 and references herein]. Improvements in the battery performance can be achieved by reconfiguring the electrode materials currently employed in 2-D batteries into 3-D architectures. The use of commercially available carbon foams as framework for cathode materials offers several advantages such as good inter-particle conductivity, an efficient transport route for the solvated ions that can be used for manufacturing lithium ion batteries.

In this work we report the characterization of carbon - $\mathrm{LiMPO}_{4}$ composites $(\mathrm{M}=\mathrm{Fe}, \mathrm{Mn}, \mathrm{Co}, \mathrm{Ni})$ prepared by a Pechini-assisted sol-gel method.

\section{Experimental}

The experimental procedures for the preparation and characterizations of the samples have been previously reported [3-5]. The samples in the $\mathrm{LiMPO}_{4}$ system $(\mathrm{M}=\mathrm{Fe}, \mathrm{Co}, \mathrm{Ni})$ have been prepared by dissolving in water lithium acetate, iron sulfate (cobalt acetate, nickel acetate) as precursors (molar ratio 1:1) with citric acid ( $2 \times$ mol [Fe, $\mathrm{Co}, \mathrm{Ni}]$ ), then adding phosphoric acid in the equimolar ratio with $\mathrm{Li}$ ions. Pure water, due to the rheological properties, favored the infiltration of the ions containing solution into the porous architecture of the foams. The composites were prepared by soaking the commercial foams in the starting aqueous solution at $70^{\circ} \mathrm{C}$ for $2-4 \mathrm{~h}$. After rinsing with distillate water the samples have been annealed in nitrogen (for $\mathrm{M}=\mathrm{Fe}$ ) and air/nitrogen (for $\mathrm{M}=$ $\mathrm{Co}, \mathrm{Ni}$ ). The Mn-containing system was prepared by dissolving the precursors in ethylene-glycol stirred at room temperature, then by adding the commercial carbon nanofibers. Finally the composites were annealed at $500^{\circ} \mathrm{C}$ for $12 \mathrm{~h}$ in nitrogen.

The structural analysis of the samples was performed by X-ray powder diffraction (XRD) on powders prepared under very similar conditions, the morphological investigation was carried out by High-Resolution Electron Microscopy (HREM) and the electrochemical studies (e.g.: cyclic voltammetry $(\mathrm{CV})$ ) have been carried out with a multichannel potenstiostatic-galvanostatic system. For the measurements, Swagelok-type cells were assembled in an argon-filled dry box with water and oxygen less than $5 \mathrm{ppm}$. In the cell, Li metal was used as anode, SelectiLyte LF30 as electrolyte [5] and Celgard®2500 as separator.

\section{Results and discussion}

Because of the different processes used to prepare the $\mathrm{LiMPO}_{4} / \mathrm{C}$-nanostructures composites $(\mathrm{M}=$ $\mathrm{Fe}, \mathrm{Co}, \mathrm{Ni}, \mathrm{Mn}$ ), this paragraph has been divided as follows:

a) Characterization of the $\mathrm{LiMPO}_{4} / \mathrm{C}$-nanotubes composites in non-aqueous solutions (polyol);

b) Characterization of the $\mathrm{LiMPO}_{4} / \mathrm{C}$-foams composites in aqueous solutions.

The results of the structural, morphological and electrochemical investigations of the prepared composites will be discussed more in detail in the following paragraphs.

\section{1 $\mathrm{LiMnPO}_{4} / \mathrm{C}$-nanotube composites}

A typical XRD pattern of the pristine $\mathrm{LiMnPO}_{4} / \mathrm{C}$-nanotubes composites is shown in Figure 1a. All of the reflections could be indexed on the basis of the orthorhombic olivine structure (space group: Pnma) [6], indicating the formation of phase pure sample. The sharp diffraction peaks illustrate the highly crystalline nature of the $\mathrm{LiMnPO}_{4}$ phase achievable by the sol-gel process within a short 
reaction time without post annealing at elevated temperatures. The morphological investigation reveals the presence of naked nanotubes (Figure 1b) between the crystals of $\mathrm{LiMnPO}_{4}$. Following
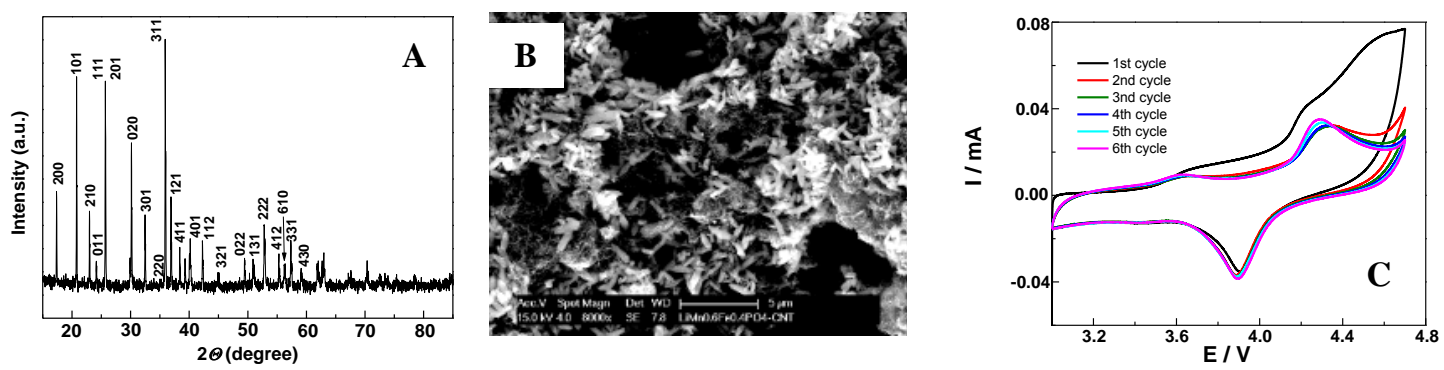

Fig. 1. A) XRD pattern, B) HREM micrograph and C) voltammetric curve of the $\mathrm{LiMnPO}_{4} / \mathrm{C}$-nanotubes composites

reasons might account for this difference: the olivine crystals can typically reach the $\mu \mathrm{m}$ in size, whereas the carbon nanotubes are ca. $100 \mathrm{~nm}$ in size. Hence, self-assembling of $100 \mathrm{~nm}$ is feasible, but this kind of packing is hardly achievable with larger crystals. Further the chemical interactions between the surface of the carbon nanotubes with phosphate surface might be not so efficient to allow a stabile interaction and consequently a growth of the olivine crystals on the nanotubes surface [7]. A typical cyclic voltammogram (CV) cycled in the range 3.0-4.7 V is shown in Figure 1c. The $\mathrm{CV}$ curves show that the shape of the first cycle is slight different while CV-profiles are reduplicated from the second cycle as revealed by the very close values of the mean peak maxima in the cathodic region at $3.90 \mathrm{~V}$. The mean peak maximum in the oxidation region of the first cycle lies at $4.20 \mathrm{~V}$, while the mean peak maxima lye around $4.30 \mathrm{~V}$ from the second cycle on. This result is in good agreement with previous cyclic voltammetry investigations on $\mathrm{LiMnPO}_{4}$ [8]. The difference in the shape of the first cycle of the voltammetric curves can depend upon several parameters such as structural and morphological changes of the cathode and anode materials, chemical reactions occurring within the electrolyte, at the electrolyte-anode and electrolyte-cathode interfaces. We can reasonably assume that the marked capacity observed after the first cycle can be due to surface reactions involving the change of the structure of LMP from olivine to an amorphous phase, the formation of a passive, solid-electrolyte interface (SEI) layer on the surface of both the cathode and the anode materials. This also explains the lower specific capacity $\left(70 \mathrm{mAhg}^{-1}\right)$ than the theoretical one $\left(171 \mathrm{mAhg}^{-1}\right)$ delivered by the galvanostatic measurements.

\section{2 $\mathrm{LiFePO}_{4} / \mathrm{C}$-Foams composites}

The XRD analysis (Figure 2a) shows the presence of the olivine-like structured $\mathrm{LiFePO}_{4}$ as major crystalline phase: however crystalline reflections, attributed to $\mathrm{Li}_{4} \mathrm{P}_{2} \mathrm{O}_{7}$ as secondary phase, have been also detected (indicated with + in Figure 2a). A typical HREM micrograph of the $\mathrm{LiFePO}_{4} /$
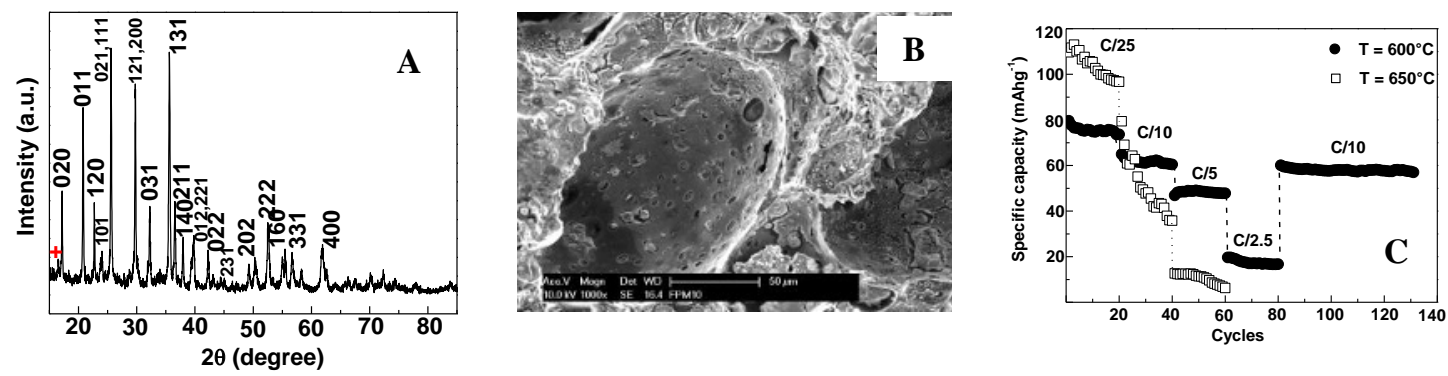

Fig. 2. A) XRD pattern of $\mathrm{LiFePO}_{4}$ powders, B) HREM micrograph and C) discharge capacity of the $\mathrm{LiFePO}_{4} / \mathrm{C}$-foam composites 
carbon foam composites is shown in Figure 2b. The micrograph shows a very homogeneous coating of the foam surface. By soaking, the foam surface is covered by a continuous layer of liquid in which the $\mathrm{Li}^{+}, \mathrm{Fe}^{2+}$ and $\left(\mathrm{PO}_{4}\right)^{3-}$ ions are uniformly distributed. The slow evaporation of the solvent leads to a "uniform" layer on the foam surface. After annealing under nitrogen, the formation of a uniform layer of crystalline $\mathrm{LiFePO}_{4}$ can be observed (Figure 3c) [9].

The discharge capacities for the carbon foam/LiFePO $\mathrm{H}_{4}$ composites are presented in Figure 2c. The annealing temperature had a significant effect on the capacity of the battery. The optimal temperature was determined to be $600^{\circ} \mathrm{C}$ with a capacity of $85 \mathrm{mAhg}^{-1}$ attained at a discharge rate of $\mathrm{C} / 25$. Although the sample annealed at $650^{\circ} \mathrm{C}$ delivered at the beginning a capacity of $110 \mathrm{mAhg}^{-1}$ at the discharge rate of $\mathrm{C} / 25$, a capacity loss was observed during the cycling. This difference is even more evident at the slow discharge rate of $\mathrm{C} / 10$. This behavior is likely due to the different morphological features of the composite materials in dependence on the temperature. The different morphology of the composites increases the polarization of the cathode material during the cycling. The polarization is related to the diffusion resistance within the composite electrode [10].

\section{3 $\mathrm{LiCoPO}_{4} / \mathrm{C}$-Foams and $\mathrm{LiNiPO}_{4} / \mathrm{C}$-Foams composites}

Among the $\mathrm{LiMPO}_{4}(\mathrm{M}=\mathrm{Fe}, \mathrm{Mn}, \mathrm{Ni}$ and $\mathrm{Co})$ systems, $\mathrm{LiCoPO}_{4}$ has the highest redox potential. $\mathrm{LiCoPO}_{4}$ is the only example of this class of materials that is suitable for $5 \mathrm{~V}$ performances. In fact it can be considered as one of the best examples of $5 \mathrm{~V}$ cathode materials because of its high specific capacity and voltage. Studies on $\mathrm{LiCoPO}_{4}$ powders and composites are scarce because the existing preferred nonaqueous electrolytes are found to be unstable in the high-voltage range $(\geq 4.8 \mathrm{~V})$ where cobalt reduction/oxidation reactions can occur. Furthermore, a severe capacity fading during cycling has limited the use of this material in practical applications. As result, less attention has been paid toward the development of $\mathrm{LiCoPO}_{4}$ cathode in lithium batteries using non-aqueous electrolytes.

The XRD diffractogramm (Figure 3a) of a $\mathrm{LiCoPO}_{4} / \mathrm{C}$-foam composite annealed at $730^{\circ} \mathrm{C}$ for $5 \mathrm{~h}$, reveals the presence of the olivine-like structured $\mathrm{LiCoPO}_{4}$ as single crystalline phase. At higher annealing times crystalline reflections, attributed to $\mathrm{Li}_{4} \mathrm{P}_{2} \mathrm{O}_{7}$ as secondary phase, have been also detected [5]. The morphological investigation of the $\mathrm{LiCoPO}_{4} / \mathrm{C}$-foam composites revealed the
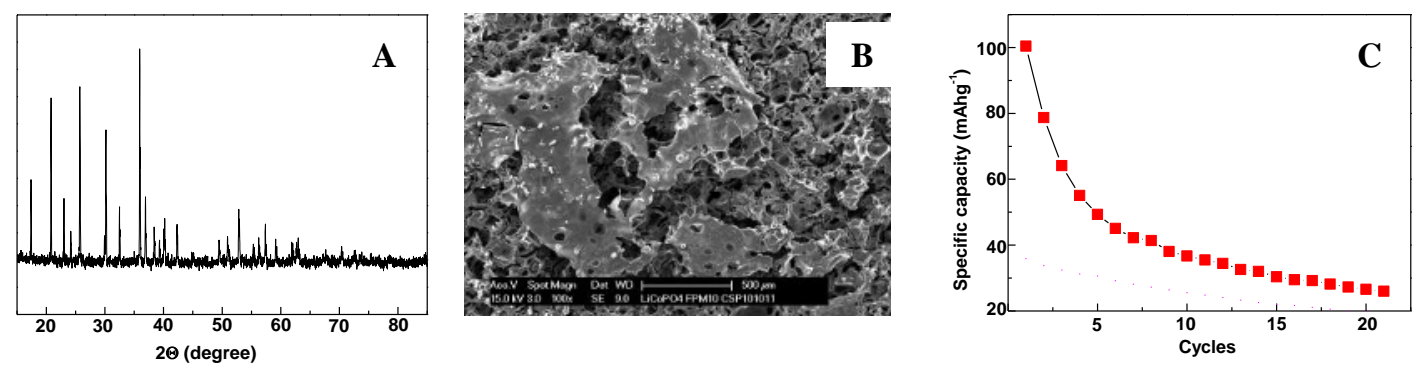

Fig. 3. A) XRD pattern of $\mathrm{LiCoPO}_{4}$ powders, B) HREM micrograph and C) voltammetric curve of the $\mathrm{LiCoPO}_{4} / \mathrm{C}$-foam composites

presence of layer which is not uniformly distributed on the surface of the foam (Figure 3B). By soaking, the foam surface is supposed to be covered by a continuous layer of liquid in which the $\mathrm{Li}^{+}$, $\mathrm{Co}^{2+}$ and $\left(\mathrm{PO}_{4}\right)^{3-}$ ions are uniformly distributed. The slow evaporation of the solvent should lead to a "uniform" layer on the foam surface. However other factors, such as the viscosity of the solution, seem to influence the morphology of the $\mathrm{LiCoPO}_{4}$ layers on the carbon foams surface. Unlike the Fe-containing solutions, the Co-containing solutions tend to turn to gel much faster under similar conditions of temperature and pressure giving rise to the $\mathrm{LiCoPO}_{4}$ phase deposited on the surface of the foam.

The discharge capacity (measured at $\mathrm{C} / 25$ discharge rate and at room temperature) for the $\mathrm{LiCoPO}_{4}$ /C-foam composites after annealing at $\mathrm{T}=730^{\circ} \mathrm{C}$ for $\mathrm{t}=12 \mathrm{~h}$ is shown in Figure $3 \mathrm{C}$. Although the 
value of the capacity reaches $100 \mathrm{mAhg}^{-1}$ at the first cycle, a great decrease of the capacity as a function of the cycle numbers has been observed. The electrochemical activity of the $\mathrm{LiCoPO}_{4}$ system is still a controversial debate and has not been fully understood. Extensive investigations on the electrochemical properties of the $\mathrm{Li}_{\mathrm{x}} \mathrm{CoPO}_{4}$ system, prepared by sol-gel process, claim that a two-step delithiation process occurs and that it is an intrinsic property of the system [11]. Furthermore, the in situ and ex situ XRD investigations showed that the crystalline phase was only a lithium-poor phase; no "CoPO 4 " was identified even though $\mathrm{LiCoPO}_{4}$ was fully charged [12]. The lithium extraction-insertion in $\mathrm{LiCoPO}_{4}$ was demonstrated to proceed in a reversible manner. The limited electronic/ionic transport, well-known for olivine-type metallophosphates, can contribute to the loss in capacity and according to Bramnik et al. [12] the discharge capacity should increase at low currents rates. This behavior was explained by the contribution of the electrolyte decomposition, which is more significant at slow charging of the cell. In fact, the degradation of the electrolyte on the cathode side may cause a limitation in mass transport on the cathode/electrolyte interface. Our experimental results and experience have shown that the influence of the electrolyte decomposition on the capacity fade of the $\mathrm{LiCoPO}_{4}$ system can be considered minimal [5]. An additional factor to be considered can be the growth of secondary phases (particularly $\mathrm{Co}_{2} \mathrm{P}$ as confirmed by the XRD analysis) on the grain boundaries that could behave like "resistors" allowing the electron flow but adding a further potential on the surface that would inhibit the Li-ions transfer. This additional surface potential may be the reason of the degradation of the electrochemical performance of the system with the time [13].

Information available about the electrochemical performance of $\mathrm{LiNiPO}_{4}$ are very limited due to the difficulty in obtaining a pure phase of lithium nickel phosphate [14]. The studies [15-17] on this material have mostly shown that lithium nickel phosphate is not electrochemically active; no lithium can be subsequently intercalated even if it is charged over $5.2 \mathrm{~V}$. On the other hand, Wolfenstine et al. [17] have reported the electrochemical activity of $\mathrm{LiNiPO}_{4}$ powders prepared by solid state reaction under high purity argon gas with the addition of a carbon coating. The voltammetric curve exhibited both a significant reduction peak at $\sim 5.1 \mathrm{~V}$. The observation that no oxidation/reduction peaks were exhibited when $\mathrm{LiNiPO}_{4}$ was heated under argon, suggested that this material has a very low intrinsic electrical conductivity and hence, additional treatments such as carbon coating or metal doping are required for $\mathrm{LiNiPO}_{4}$ to exhibit $\mathrm{Li}$ insertion/deinsertion.

The XRD diffractogramm (Figure $4 \mathrm{~A}$ ) of a $\mathrm{LiNiPO}_{4} / \mathrm{C}$-foam composite annealed at $800^{\circ} \mathrm{C}$ for $5 \mathrm{~h}$ in air, indiates the presence of the olivine-like structured $\mathrm{LiNiPO}_{4}$ as major crystalline phase. Crystalline reflections, attributed to $\mathrm{LiPO}_{3}$ (o) and $\mathrm{NiO}$ as secondary phases have been also detected. Unfortunately such annealing conditions may not be utilized for the preparation of the composites due to the scarce stability of the graphitic carbon foams in oxidizing atmospheres (air, oxygen) above $300^{\circ} \mathrm{C}$. Following the results obtained with the Co-containing composites, the $\mathrm{LiNiPO}_{4} / \mathrm{C}$-foam
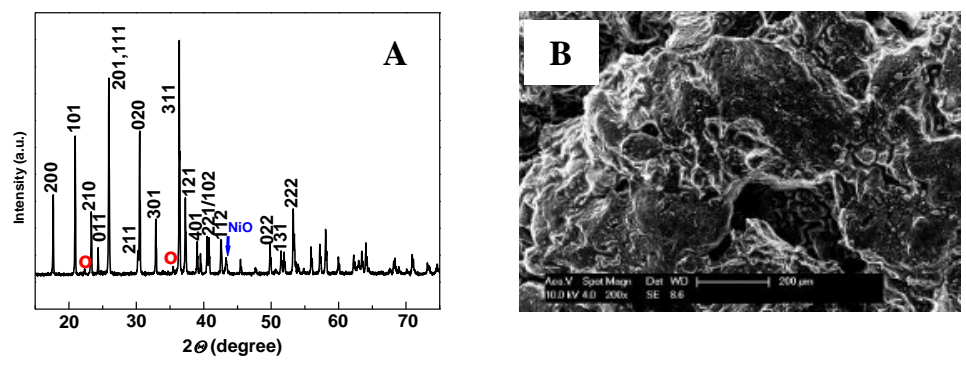

Fig. 4. A) XRD pattern of $\mathrm{LiNiPO}_{4}$ powders, B) HREM micrograph of the $\mathrm{LiNiPO}_{4} / \mathrm{C}$-foam composites

composites have been prepared after pre-annealing in air at and then annealing in nitrogen [18]. The morphological investigation of the $\mathrm{LiNiPO}_{4} / \mathrm{C}$-foam composites revealed the presence of a homogenous coating on the surface of the foam (Figure 3B). By soaking, the foam surface is covered by a continuous layer of liquid in which the $\mathrm{Li}^{+}, \mathrm{Ni}^{2+}$ and $\left(\mathrm{PO}_{4}\right)^{3-}$ ions are uniformly distributed. The 
slow evaporation of the solvent leads to a "uniform" layer on the foam surface. After annealing under nitrogen, the formation of a uniform layer of crystalline $\mathrm{LiNiPO}_{4}$ can be observed.

The preliminary results of the electrochemical performance of the $\mathrm{LiNiPO}_{4} / \mathrm{C}$-foam composites indicate the presence of polarization in the composites. This polarization emerges from a combination of Li-diffusion rates and the intrinsic activation barrier of transferring electrons which could be high due to the small size of the particles that is to say to the high interparticle surface. Furthermore, the voltammetric curves can depend upon several parameters such as structural and morphological changes of the cathode and anode materials, chemical reactions occurring within the electrolyte, at the electrolyte-anode and electrolyte-cathode interfaces. The influence of these parameters has been investigated in several systems as $\mathrm{LiCoO}_{2}, \mathrm{LiMnO}_{4}$ and $\mathrm{LiFePO}_{4}$ however, we have found no data concerning the $\mathrm{LiNiPO}_{4}$ system. Further electrochemical measurements are running in order to understand the mechanism of the Li-ions intercalation/deintercalation processes of this system.

Further investigations are still necessary to improve the properties of the $\mathrm{LiMPO}_{4}$ systems in order to meet the requirements for industrial applications.

\section{Conclusions}

This work describes recent developments in the synthesis and characterization of composites which consist of lithium metal phosphates $\left(\mathrm{LiMPO}_{4}, \mathrm{M}=\mathrm{Fe}, \mathrm{Mn}, \mathrm{Co}, \mathrm{Ni}\right)$ coated on nanostructured carbon supports (unordered nanofibers, foams). The composites have been prepared by soaking the foams in the starting solution, containing the ions.

The olivine phase was identified by XRD analysis performed on powders, prepared under similar conditions. The surface investigation on the prepared composites has revealed a dependence of the morphology upon the transition metal used as well as the annealing conditions. The composites showed a homogeneous coating of the olivine phase on the porous nanoarchitecture of the foams after soaking and annealing.

The electrochemical measurements showed a good reproducibility of the peaks in the voltammetric plots as well as narrow oxidation/reduction potential difference, which is representative of the good reversibility of the lithium extraction/insertion in the materials. The composites delivered a discharge capacity at a discharging rate of $\mathrm{C} / 25$ and $\mathrm{RT}$ of $85 \mathrm{mAhg}^{-1}$ for $\mathrm{M}=\mathrm{Fe}$, of $70 \mathrm{mAhg}^{-1}$ for $\mathrm{M}=\mathrm{Mn}$ and of $100 \mathrm{mAhg}^{-1}$ for $\mathrm{M}=\mathrm{Co}$ respectively. More investigations are necessary to improve the performance of the Ni-containing system.

In the future, improvements to the electrochemistry may be achieved by optimizing the coating of lithium metal phosphates surrounding the carbon foam. This would increase the carbon-LiMPO interface and potentially improve the charge transfer kinetics. Further investigation into the application as e.g. supercapacitor electrode material may also be promising.

\section{Acknowledgements}

The Authors thank the Deutsche Forschungsgemeinschaft (DFG) (DFG-Forschungsinitiative Project: $P A K-177)$ for the financial support during this work. The DFG promote and support financially the publication of the scientific results obtained during the projects. The DFG had no involvement in study design; in the collection, analysis and interpretation of data; in the writing the report, and in the decision to submit the paper for publication. 


\section{References}

[1] D.W. Han, Y.M. Kang, R.Z. Yin, M.S. Song, H.S. Kwon, Electrochem. Commun. 11, 137 (2009)

[2] W.F. Howard, R.M. Spotnitz, J. Power Sources 165, 887 (2007)

[3] L. Dimesso, C. Förster, W. Jaegermann, J. P. Khanderi, H. Tempel, A. Popp, J. J. Schneider, A. Sarapulova, D. Mikhailova, L. A. Schmitt, S. Oswald and H. Ehrenberg, Chem. Soc. Rev. (2012), in press, DOI: 10.1039/c2cs15320c

[4] L. Dimesso, C. Spanheimer, S. Jacke, W. Jaegermann, J. Power Sources 196, 6729 (2011)

[5] L. Dimesso, G. Cherkashinin, C. Spanheimer, W. Jaegermann, J. Alloys Compd. 516, 119 (2012)

[6] A.V. Murugan, T. Muraliganth, P.J. Ferreira, A. Manthiram, Inorg. Chem. 48, 946 (2009)

[7] L. Kavan, R. Bacsa, M. Tunckol, P. Serp, S.M. Zakeeruddin, F. Le Formal, M. Zukalova, M. Graetzel, J. Power Sources 195, 5360 (2010)

[8] Z. Bakenov, I. Taniguchi, J. Power Sources 195, 7445 (2010)

[9] L. Dimesso, S. Jacke, C. Spanheimer, W. Jaegermann, J. Alloys Compd. 509, 3777 (2011)

[10] D. Choi, P. N. Kumta, J. Power Sources 163, 1064 (2007)

[11] J. Xie, N. Imanishi, T. Zhang, A. Hirano, Y. Takeda, O. Yamamoto, J. Power Sources 192, 689 (2009)

[12] N.N. Bramnik, K. Nikolowski, C. Baehtz, K.G. Bramnik, H. Ehrenberg, Chem. Mater. 19, 908 (2007)

[13] L. Dimesso, S. Jacke, C. Spanheimer, W. Jaegermann, J. Solid State Electrochem. 16, 911 (2012)

[14] S. Okada, S. Sawa, M. Egashira, J. Yamaki, M. Tabuchi, H. Kageyama, T. Konishi, A. Yoshino, J. Power Sources 97-98, 430 (2001)

[15] C.A.J. Fisher, V.M.H. Prieto, M.S. Islam, Chem. Mater. 20, 5907 (2008)

[16] O.G. Moreno, M.A. Vega, F.G. Alvarado, J.G. Jaca, J.M.G. Amores, M.L. Sanjuan, U. Amador, Chem. Mater. 13, 1570 (2001)

[17] J. Wolfenstine, J. Allen, J. Power Sources 142, 389 (2005)

[18] L. Dimesso, C. Spanheimer, D. Becker, W. Jaegermann, Nanotoday (2012), submitted 